\title{
Perkembangan Rencana Pembangunan Kawasan Industri Sentolo (2005-2013)
}

\author{
Dahana Pamungkas ${ }^{1}$, Suryanto ${ }^{2}$ \\ Magister Perencanaan Kota dan Daerah (MPKD) \\ Fakultas Teknik Universitas Gadjah Mada (UGM) \\ E-mail: dahana.pamungkas@mail.ugm.ac.id', soeryanto@ugm.ac.id ${ }^{2}$
}

\begin{abstract}
In this paper, the authors examined the development of industrial estate in Sentolo, Kulon Progo Regency, Yogyakarta Special Region (DIY). By using qualitative deductive method, the authors analyzed more about the development of industrial estate in Sentolo. Industrial estate development has become one of the government's main programs in order to accelerate economic development in the regions. Considering its importance, Yogyakarta Special Region Province planned to develop industrial estate in Sentolo, Kulon Progo. On its development progress, although Sentolo had suitable location for industrial estate, there was no implementation until now. It was because there was no single fixed master plan to guide the industrial estate development and no specific institution which handled the development processes. To implement this industrial estate development in Sentolo, there were several things the government of DIY needed to implement: applying the fixed master plan industrial estate development and establishing special division for developing industrial estate.
\end{abstract}

Keywords: Industrial Estate, Plan

Abstrak: Pada tulisan ini, penulis meneliti tentang perkembangan kawasan industri di Sentolo, Kabupaten Kulon Progo, Daerah Istimewa Yogyakarta (DIY). Dengan menggunakan metode deduktif kualitatif, penulis menganalisa lebih lanjut mengenai perkembangan kawasan industri yang ada di Sentolo. Pembangunan kawasan industri menjadi salah satu program utama pemerintah untuk mempercepat pembangunan ekonomi di daerah. Mengingat pentingnya hal tersebut, DIY berencana untuk mengembangkan kawasan industri di Sentolo, Kulon Progo. Dalam perkembangannya, meski Sentolo memiliki lokasi yang cocok untuk kawasan industri, belum ada implementasi pembangunan kawasan industri hingga saat ini. Hal ini dikarenakan tidak ada satu pun master plan yang tetap untuk dijadikan pedoman pengembangan kawasan industri serta tidak adanya institusi khusus yang menangani proses pembangunan kawasan industri. Untuk melaksanakan pengembangan kawasan industri ini di Sentolo, ada beberapa hal yang harus dilakukan: menerapkan master plan pengembangan kawasan industri yang pasti dan membentuk divisi khusus untuk pengembangan kawasan industri.

Kata kunci: Kawasan Industri, Rencana

\subsection{Latar Belakang}

Pembangunan nasional berbasis wilayah tidak hanya membutuhkan ekspansi ekonomi, namun juga pemerataan hasil pembangunan ekonomi dan sosial di seluruh negeri. Selanjutnya, pentingnya untuk mengembangkan kawasan industri di setiap wilayah di Indonesia yang menghasilkan dampak positif seperti pembangunan daerah. Pembangunan Kawasan Industri Sentolo telah diusulkan selama beberapa tahun namun sayangnya belum diimplementasikan hingga saat ini. Lamanya proses implementasi membuat penulis mengeksplorasi lebih dalam tentang proses pembangunan Industri Sentolo.

Untuk mempercepat dan memperluas pembangunan ekonomi di daerah, pengembangan sentra pertumbuhan ekonomi dilakukan dengan memanfaatkan potensi dan keunggulan yang dimiliki oleh suatu daerah, salah satunya dengan pengembangan kawasan industri. Pembangunan kawasan industri menjadi salah satu program utama pemerintah untuk mengembangkan kawasan kawasan strategis. Tujuan pengembangan kawasan industri seperti yang dimuat dalam Peraturan Pemerintah No. 24 tahun 2009 tentang Kawasan Industri adalah: (a) mengendalikan pemanfaatan lahan, (b) meningkatkan upaya pengembangan industri yang berwawasan lingkungan, (c) mempercepat pertumbuhan industri regional, (d) meningkatkan daya saing industri dan investasi, dan (e) memastikan rencana lokasi dan pembangunan infrastruktur dengan koordinasi yang baik antar sektor terkait. 
Menurut kerangka kerja dan pedoman yang ditetapkan oleh Peraturan Pemerintah No. 24 tahun 2009 ini, Indonesia telah memajukan pengembangan kawasan industri dan tujuh puluh tujuh perkebunan di seluruh negeri telah dikembangkan hingga saat ini. Namun, kawasan industri Indonesia belum diupayakan secara efektif sebagai pendorong kuat pembangunan ekonomi daerah dengan jumlah yang terbatas tidak cukup untuk mempengaruhi ekonomi secara keseluruhan.

\section{Tabel 1. Jumlah Kawasan Industri Menurut} Provinsi di Indonesia

\begin{tabular}{|c|l|c|}
\hline No & \multicolumn{1}{|c|}{ Lokasi } & \multicolumn{1}{|c|}{$\begin{array}{c}\text { Jumlah } \\
\text { Kawasan } \\
\text { Industri }\end{array}$} \\
\hline 1 & Prov. Jawa barat & 30 \\
\hline 2 & Pulau Batam & 12 \\
\hline 3 & Prov. Jawa Barat & 9 \\
\hline 4 & Prov. Banten & 6 \\
\hline 5 & DKI Jakarta & 5 \\
\hline 6 & Prov. Jawa Timur & 3 \\
\hline 7 & Prov. Sumatera Utara & 3 \\
\hline 8 & Prov. Kalimantan Timur & 2 \\
\hline 9 & Prov. Sulawesi Tenggara & 2 \\
\hline 10 & Pulau Bintan & 1 \\
\hline 11 & Prov. Riau & 1 \\
\hline 12 & Prov. Sumatera Barat & 1 \\
\hline 13 & Prov. Sulawesi Tengah & 1 \\
\hline 14 & Prov. Sulawesi Utara & 1 \\
\hline 15 & Prov. DIY & - \\
\hline & Total & 77 \\
\hline
\end{tabular}

Sumber: "List of Indonesian Industrial Estates" ASEAN-Japan Centre,http://www.asean.or.jp/ja/asean/know/country/indonesi a/invest/industrialestate/index.html/

Berdasarkan Peraturan Pemerintah No. 24 Tahun 2009 yang sudah dijelaskan di atas, Daerah Istimewa Yogyakarta (DIY) merancang untuk mengembangkan kawasan industri yang berlokasi di Sentolo. Kawasan ini memiliki potensi produk industri, yang meliputi industri pengolahan hasil pertanian, kerajinan tangan, pengolahan, jasa, atau lainnya, baik mikro, kecil dan menengah yang sampai saat ini potensi ini belum dapat dikembangkan secara optimal.

Sesuai dengan arahan Peraturan Pemerintah Nomor 24 Tahun 2009, setiap industri baru yang berdiri harusi berada di dalam kawasan industri. Selain itu, DIY merupakan satu-satunya Provinsi di Pulau Jawa yang belum memiliki kawasan industri hingga saat ini. Dalam hal ini diperlukan perencanaan yang matang dan mencakup aspek-aspek pendukung strategis.

Pengembangan potensi di Sentolo ini dioptimalkan melalui pendirian Kawasan Industri Sentolo, yang diharapkan bisa menjadi pusat pertumbuhan baru di Yogyakarta yang dapat mempercepat pertumbuhan kawasan, terutama untuk masa depan di Kulon Progo.
Kawasan ini rencananya juga akan dikembangkan sebagai Bandara Internasional, pelabuhan perikanan Tanjung Adikarto, dan pengembangan pertambangan pasir industri sektor industri, yang mendukung Kawasan Industri Sentolo. Untuk itu, dibutuhkan jaringan infrastruktur untuk pengembangan kawasan industri di Sentolo, salah satunya adalah jaringan pergerakan daerah (jaringan jalan utama) dan nasional (Jalan Jalur Lintas Selatan/JJLS).

Di Kulon Progo, pengembangan kawasan industri telah dimulai pada tahun 2005 oleh Dinas Pekerjaan Umum DIY dan dilanjutkan dengan Master Plan Pengembangan Kawasan Industri Sentolo yang disusun oleh Badan Penanaman Modal dan Kerjasama DIY pada tahun 2013. Namun, hingga saat ini belum ada tindak lanjut dan implementasi terkait pengembangan kawasan industri ini.

Penelitian ini mencoba menggali faktorfaktor yang diperlukan agar berhasil mengatasi keseluruhan proses pengembangan kawasan industri dan memberikan arahan untuk memandu pengembangan kawasan industri yang sukses bagi Indonesia terutama di DIY untuk meningkatkan industrialisasi regional dalam kaitannya dengan pembangunan ekonomi nasional.

Tujuan dari penelitian ini adalah:

1. Menguraikan proses pengembangan dan mengevaluasi rencana kawasan industri di Sentolo.

2. Mengidentifikasi faktor-faktor yang mempengaruhi pelaksanaan kawasan industri Sentolo.

3. Menggambarkan prospek pengembangan kawasan industri Sentolo.

Manfaat dari penelitian ini adalah:

1. Memberikan pemahaman kritis tentang pengembangan kawasan industri.

2. Memberikan rekomendasi bagi pemerintah daerah mengenai pengembangan kawasan industri.

Pertimbangan yang dibutuhkan dalam perencanaan kawasan industri oleh pemerintah sehingga memberikan dampak yang positif bagi pengembangan kawasan industri di masa depan. Selain itu, akan memberikan masukan kepada pemerintah terkait dengan lokasi pengembangan kawasan industri.

\subsection{Landasan Teori}

\subsubsection{Definisi Kawasan Industri}

Beragam istilah kawasan industri didefinisikan tidak hanya oleh para ilmuwan tetapi juga organisasi internasional dan peraturan resmi. Definisi ini akan dibahas sebagai berikut. William Bredo (1960) dalam 
Gurusamy (1994) mendefinisikan kawasan industri sebagai sebidang tanah yang dikembangkan dan dibagi menjadi beberapa bagian sesuai dengan rencana komprehensif dengan penyediaan jalan, transportasi dan utilitas umum untuk penggunaan aktivitas industri.

Berdasarkan Industrial Development Handbook (1975) dalam Wahidi (2014), yang dimaksud dengan Kawasan Industri atau Industrial Estate atau juga sering disebut sebagai Industrial Park adalah sebuah kawasan industri di atas tanah yang cukup luas, yang secara administrasi dikontrol oleh seorang atau sebuah lembaga yang cocok untuk kegiatan industri, karena lokasinya, topografinya, zoning yang tepat, ketersediaan semua infrastrukturnya (utilitas), dan kemudahan aksesibilitas transportasi.

Selain itu, Perserikatan Bangsa-Bangsa (PBB) (1966) dalam Gurusamy (1994) mendefinisikan kawasan industri sebagai pengelompokan perusahaan industri yang direncanakan, menawarkan lokasi yang dikembangkan, dan menyediakann layanan dan fasilitas kepada penghuninya (tenant), atau rencana pengelompokan perusahaan industri yang menawarkan bangunan pabrik standar didirikan sebelum permintaan dan berbagai layanan dan fasilitas kepada penghuninya.

Peraturan Pemerintah No. 24 tahun 2009 tentang kawasan industri mendefinisikan bahwa kawasan industri adalah pusat kegiatan industri yang dilengkapi dengan sarana dan prasarana yang dikembangkan dan dikelola oleh perusahaan kawasan industri yang memiliki izin usaha industri.

Dari berbagai definisi yang disebutkan di atas, sebuah "kawasan industri" secara kompak didefinisikan sebagai sebidang tanah yang dikembangkan untuk mengakomodasi industri manufaktur dan industri lainnya berdasarkan rencana tertentu yang dirumuskan secara resmi oleh pemerintah yang bertujuan untuk pengembangan industri regional yang dilengkapi dengan fasilitas infrastruktur, pelayanan administrasi, pelayanan kesejahteraan dan sebagainya untuk mendukung penyewa (tenant) agar dapat berproduksi secara maksimal.

\subsubsection{Keunggulan Pengembangan Kawasan Industri}

Menurut Gurusamy (1994), kawasan industri memiliki banyak keunggulan yang secara khusus berkontribusi terhadap berbagai bidang untuk mendorong pembangunan ekonomi, antara lain: (1) Promosi industri kecil, (2) Percepatan pertumbuhan, (3) Penyediaan fasilitas dan insentif, (4) Mobilisasi investasi awal, skala ekonomi, (5) Aglomerasi dan ekonomi eksternal, (6) Penggunaan lahan secara ekonomis, (7) Promosi pengembangan industri, (8) Pembangunan daerah,

Penyuluhan industri, (10) Pertumbuhan jaringan, (11) Kerjasama timbal balik, (12) Pengembangan perkotaan yang direncanakan, (13) Penciptaan lapangan kerja dan peningkatan kesempatan kerja, (14) Peningkatan produktivitas, (15) Promosi ekspor, (16) Pembibitan untuk industri baru, dan (17) Penguatan posisi fiskal daerah.

\subsubsection{Kriteria dan Persyaratan Kawasan Industri}

Berdasarkan Berdasarkan Peraturan Menteri Perindustrian no. 40/M-IND/PER/6/2016 tentang Pedoman Teknis Pembangunan Kawasan Industri, terdapat beberapa kriteria dalam memilih lokasi kawasan industri.

Tabel 2. Kriteria Pertimbangan Pemilihan Lokasi Kawasan Industri

\begin{tabular}{|c|c|c|}
\hline No & $\begin{array}{c}\text { Kriteria Pemilihan } \\
\text { Lokasi }\end{array}$ & Faktor Pertimbangan \\
\hline 1 & Jarak ke Pusat Kota & Min. $10 \mathrm{Km}$ \\
\hline 2 & Jarak ke Permukiman & Min. 2 km \\
\hline 3 & $\begin{array}{l}\text { Jaringan transportasi } \\
\text { darat }\end{array}$ & $\begin{array}{l}\text { Jalan arteri primer atau } \\
\text { jaringan kereta api }\end{array}$ \\
\hline 4 & $\begin{array}{l}\text { Jaringan Energi dan } \\
\text { Kelistrikan }\end{array}$ & Tersedia \\
\hline 5 & $\begin{array}{l}\text { Jaringan } \\
\text { Telekomunikasi }\end{array}$ & Tersedia \\
\hline 6 & Prasarana Angkutan & $\begin{array}{l}\text { Tersedia pelabuhan laut } \\
\text { untuk kelancaran } \\
\text { transportasi logistik barang } \\
\text { maupun outlet } \\
\text { ekspor/impor }\end{array}$ \\
\hline 7 & Sumber air baku & $\begin{array}{l}\text { Tersedia sumber air } \\
\text { permukaan (sungai, } \\
\text { danau, waduk/embung, } \\
\text { atau laut) dengan debit } \\
\text { yang mencukupi }\end{array}$ \\
\hline \multirow{5}{*}{8} & \multirow{5}{*}{ Kondisi Lahan } & $\begin{array}{l}\text { Topografi: max. } 15 \% \\
\end{array}$ \\
\hline & & $\begin{array}{l}\text { Kesuburan tanah relatif } \\
\text { tidak subur (non-irigasi } \\
\text { teknis) }\end{array}$ \\
\hline & & $\begin{array}{l}\text { Pola tata guna lahan: } \\
\text { nonpertanian, non- } \\
\text { permukiman, dan non- } \\
\text { konservasi }\end{array}$ \\
\hline & & $\begin{array}{l}\text { Ketersediaan lahan } \\
\text { minimal } 50 \text { ha }\end{array}$ \\
\hline & & $\begin{array}{l}\text { Harga lahan relatif (bukan } \\
\text { merupakan lahan dengan } \\
\text { harga yang tinggi di } \\
\text { daerah tersebut) }\end{array}$ \\
\hline
\end{tabular}
IND/PER/6/2016

\subsubsection{Persyaratan Pembangunan Kawasan Industri}

Untuk mengembangkan kawasan industri, terdapat tiga tahapan yang harus dipenuhi yang disyaratkan oleh Pemerintah Pusat, yang dipaparkan sebagai berikut: 
Tabel 3. Persyaratan Kawasan Industri Berdasarkan Peraturan dari Pemerintah

\begin{tabular}{|l|l|}
\hline \multicolumn{1}{|c|}{ TAHAPAN } & \multicolumn{1}{c|}{ RINCIAN } \\
\hline \multirow{4}{*}{ PERSIAPAN } & Pemilihan Lokasi \\
\cline { 2 - 2 } PENGEMBANG- & Penyusunan Dokumen \\
\cline { 2 - 3 } AN & Pengurusan Perijinan \\
\hline \multirow{5}{*}{ PENGELOLAAN } & Pembebasan Lahan \\
\cline { 2 - 2 } & $\begin{array}{l}\text { Penyusunan Perencanaan Detail } \\
\text { Engineering Design (DED) }\end{array}$ \\
\hline & Kelembagaan Kawasan Industri \\
\cline { 2 - 2 } & Sistem Manajemen \\
\cline { 2 - 2 } & $\begin{array}{l}\text { Pelaksanaan Tata Tertib Kawasan } \\
\text { Industri (Estate Regulation) }\end{array}$ \\
\cline { 2 - 2 } & Pelayanan kepada Tenan \\
\cline { 2 - 2 } & Pemasaran \\
\cline { 2 - 2 } & Pengembangan Usaha \\
\cline { 2 - 2 } & Pengelolaan Lingkungan \\
\cline { 2 - 3 } & $\begin{array}{l}\text { Kepedulian Sosial dan } \\
\text { Pemberdayaan Masyarakat }\end{array}$ \\
\cline { 2 - 3 } & $\begin{array}{l}\text { Penyusunan dan Pelaporan Data } \\
\text { Kawasan Industri }\end{array}$ \\
\hline
\end{tabular}

Sumber : Peraturan Menteri Perindustrian no. 40/MIND/PER/6/2016

Selain itu, penulis juga mengadaptasi persyaratan pembangunan kawasan industri di Jepang $^{1}$ dan $K$ orea $^{2}$, yang dipaparkan sebagai berikut:

Tabel 4. Persyaratan Kawasan Industri berdasarkan Studi Kasus di Jepang dan Korea

\begin{tabular}{|l|l|}
\hline \multicolumn{1}{|c|}{ TAHAPAN } & \multicolumn{1}{c|}{ RINCIAN } \\
\hline FAKTOR EKSTERNAL \\
\hline \multirow{4}{*}{ LOKASI } & Akses Transportasi \\
\cline { 2 - 2 } & Infrastruktur \\
\cline { 2 - 2 } & Performa Pembiayaan \\
\cline { 2 - 2 } & Penyediaan Tenaga Kerja \\
\cline { 2 - 2 } & Lingkungan Tempat Tinggal \\
\hline \multirow{2}{*}{$\begin{array}{l}\text { KEBERADAAN } \\
\text { PESITUSI }\end{array}$} & Pemerintah Daerah \\
\cline { 2 - 2 } PENDUNG & Fasilitas Pendukung Keuangan \\
\cline { 2 - 2 } FAKTOR INTERNAL & Pengelola yang Mendukung \\
\hline \multirow{4}{*}{ PERSIAPAN } & $\begin{array}{l}\text { Perumusan Kebijakan } \\
\text { Perencanaan }\end{array}$ \\
\cline { 2 - 2 } & Pengaturan Organisasi \\
\cline { 2 - 2 } & Pengaturan Keuangan Internal \\
\hline \multirow{4}{*}{ PENGEMBANGAN } & Penyiapan Lahan \\
\cline { 2 - 2 } & $\begin{array}{l}\text { Kejelasan } \\
\text { Administratif }\end{array}$ \\
\cline { 2 - 2 } & Penyiapan Utilitas \\
\hline
\end{tabular}

${ }^{1}$ Fujimoto, K. (2013). Study on Approach of Local Government for Inviting Investment of Manufacturing Companies to Industrial Estate - Strategic Investment Invitation of Mie Prefecture. Mie University, Mie. (Japanese)

「地方自治体における工業系企業誘致の手法に関する研究

-三重県の戦略的企業誘致」

${ }^{2}$ Cho, H. (2012). Industrial Park Development Strategy and Management Practices: Ministry of Strategy and Finance, Republic of Korea.

\begin{tabular}{|l|l|}
\hline \multicolumn{1}{|c|}{ TAHAPAN } & \multicolumn{1}{c|}{ RINCIAN } \\
\hline \multirow{4}{*}{ PENGELOLAAN } & Daya Tarik Investasi \\
\cline { 2 - 2 } & Konservasi Lingkungan \\
\cline { 2 - 2 } & $\begin{array}{l}\text { Penunjukan Institusi untuk } \\
\text { Pengelolaan Kawasan Industri }\end{array}$ \\
\hline & Dukungan Utilitas \\
\cline { 2 - 2 } & Dukungan Usaha \\
\cline { 2 - 2 } & Dukungan Prosedural \\
\cline { 2 - 2 } & Penyiapan Fasilitas Pendukung \\
\cline { 2 - 2 } & Layanan Fasilitas Kemudahan \\
\hline
\end{tabular}

Sumber: Hasil Analisa Penulis berdasarkan pengembangan kawasan industri di Jepang dan Korea

\subsection{Metode Penelitian}

Penelitian ini menggunakan pendekatan atau metode deskriptif kualitatif. Penelitian ini dimulai dari teori untuk membuat suatu proporsi yang berkaitan dengan kondisi nyata. Dari teoriteori tersebut, akan dijelaskan ke dalam variabel yang berkaitan dengan masalah penelitian, sehingga memudahkan pengumpulan data. Selanjutnya, analisis didukung teori dan data kawasan industri yang diolah dan grafik untuk menentukan arah pembangunan. Kemudian, penelitian ini menentukan karakteristik data berdasarkan kebutuhan analisis.

Penelitian ini dilakukan di Sentolo, Kabupaten Kulon Progo, Indonesia. Fokus penelitian ini adalah lokasi yang diarahkan dan diusulkan sebagai kawasan industri. Kerangka penelitian dapat dilihat pada gambar berikut ini.

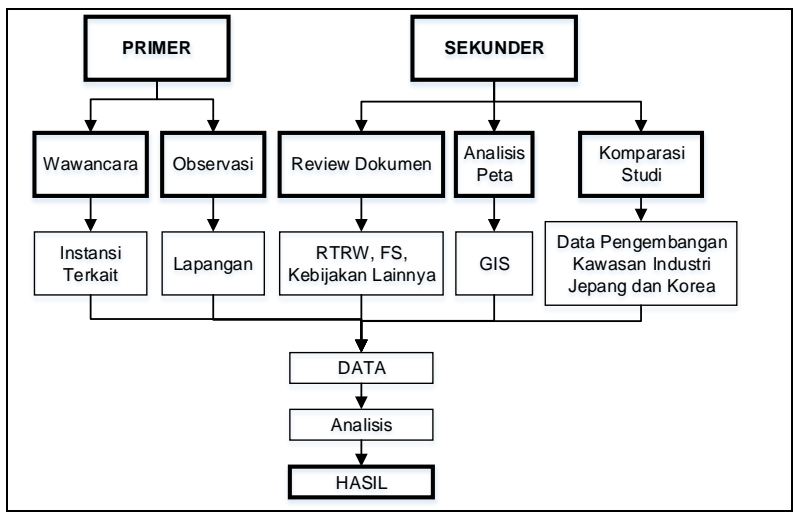

Sumber: Hasil Analisa Penulis

Gambar 1. Kerangka Penelitian

\subsection{Hasil Dan Pembahasan}

Pada bagian ini, penulis akan menguraikan rencana perkembangan kawasan industri Sentolo dari waktu ke waktu dan faktorfaktor yang mempengaruhi perkembangan kawasan industri Sentolo serta prospek ke depannya. Penulisan di bab ini digunakan untuk menjawab tujuan penelitian yang mengacu pada pengembangan kawasan industri Sentolo. 
Tabel 5. Master Plan Pembangunan Kawasan Industri di Sentolo

\begin{tabular}{|c|c|c|c|c|c|c|c|}
\hline No & Tahun & Dokumen & Institusi & $\begin{array}{c}\text { Faktor } \\
\text { Pertimbangan }\end{array}$ & $\begin{array}{l}\text { Pemilihan } \\
\text { Kriteria }\end{array}$ & Luasan & Keterangan \\
\hline 1 & 2005 & $\begin{array}{l}\text { Studi Kelayakan } \\
\text { Kawasan Industri } \\
\text { Sentolo }\end{array}$ & Dinas PU DIY & $\begin{array}{l}\text { RPJP DIY } \\
2005-2025\end{array}$ & $\begin{array}{l}\text { Pedoman } \\
\text { Teknis } \\
\text { Kawasan } \\
\text { Industri }\end{array}$ & 4765 ha & $\begin{array}{l}\text { Studi ini hanya menghitung jumlah } \\
\text { total } 7 \text { desa di Sentolo, Lendah dan } \\
\text { Galur tanpa menyebutkan } \\
\text { menganalisis kesesuaian lahan }\end{array}$ \\
\hline 2 & 2012 & $\begin{array}{l}\text { Master Plan } \\
\text { Pengembangan } \\
\text { Kawasan Industri Kulon } \\
\text { Progo }\end{array}$ & $\begin{array}{l}\text { Kementerian } \\
\text { Perindustrian } \\
\text { RI }\end{array}$ & $\begin{array}{l}\text { MP3EI, RTRW } \\
\text { Provinsi \& } \\
\text { Kabupaten }\end{array}$ & $\begin{array}{l}\text { Pedoman } \\
\text { Teknis } \\
\text { Kawasan } \\
\text { Industri } \\
\end{array}$ & 2646 ha & $\begin{array}{l}\text { Pada penelitian ini, pengembangan } \\
\text { kawasan industri diarahkan pada } \\
\text { industri baja dan pasir besi. }\end{array}$ \\
\hline 3 & 2013 & $\begin{array}{l}\text { Dokumen Perencanaan } \\
\text { Pengembangan } \\
\text { Kawasan Industri Di } \\
\text { Provinsi DIY, (Review } \\
\text { dari Master Plan } \\
\text { Kemenperin th. 2012) }\end{array}$ & $\begin{array}{l}\text { Kementerian } \\
\text { Perindustrian } \\
\text { RI }\end{array}$ & $\begin{array}{l}\text { MP3EI, RTRW } \\
\text { Provinsi \& } \\
\text { Kabupaten }\end{array}$ & $\begin{array}{l}\text { Pedoman } \\
\text { Teknis } \\
\text { Kawasan } \\
\text { Industri }\end{array}$ & 805 ha & $\begin{array}{l}\text { Kajian mereview ketidaksesuaian } \\
\text { spasial dalam penelitian sebelumnya } \\
\text { dengan RTRW. Pada penelitian ini } \\
\text { diusulkan untuk industri baja dan } \\
\text { aneka industri. }\end{array}$ \\
\hline 4 & 2013 & $\begin{array}{l}\text { Review Studi Kelayakan } \\
\text { (FS) dan Master Plan } \\
\text { Kawasan Industri } \\
\text { Sentolo }\end{array}$ & BKPM DIY & $\begin{array}{l}\text { MP3EI, RTRW } \\
\text { Provinsi } \\
\text { Kabupaten }\end{array}$ & $\begin{array}{l}\text { Pedoman } \\
\text { Teknis } \\
\text { Kawasan } \\
\text { Industri }\end{array}$ & 70.2 ha & $\begin{array}{l}\text { Jenis industri yang direncanakan } \\
\text { mencakup berbagai industri rendah } \\
\text { polutan. Tidak hanya berorientasi pada } \\
\text { industri baja tapi juga tekstil, peralatan } \\
\text { listrik, makanan, bahan kimia dan } \\
\text { industri bahan bangunan umum. }\end{array}$ \\
\hline
\end{tabular}

Sumber: Ringkasan Penulis

\subsubsection{Rencana Pembangunan Kawasan Industri Sentolo \\ Persyaratan utama pengembangan} kawasan industri adalah "perumusan kebijakan dan perencanaan" pada tahap persiapan. Kebijakan dan rencana yang solid dan konsisten harus disiapkan oleh satu institusi pemerintah. Seperti yang ditunjukkan pada tabel 4.1 di atas, masterplan Pengembangan Kawasan Industri di Kulon Progo secara terpisah disiapkan oleh beberapa otoritas/ institusi yang berbeda pada level pusat dan daerah. Ketidakseragaman ditunjukkan pada beberapa masterplan tersebut. Perbedaan pada poin luasan, lokasi dan peruntukannya, terutama sasaran industri menunjukkan bahwa perencanaan pengembangan kawasan industri di Sentolo tidak konsisten. Dengan tidak adanya satu masterplan yang matang untuk dijadikan pedoman pembangunan kawasan industri, hal ini akan mempengaruhi proses pembangunan menjadi terhambat. Dukungan institusi yang secara spesifik menangani pengembangan kawasan industri juga sangat dibutuhkan guna mempercepat proses implementasinya.

\subsubsection{Evaluasi Pengembangan Kawasan Industri di Sentolo}

Dari uraian sebelumnya, terdapat beberapa kriteria berdasarkan Peraturan Menteri Perindustrian no. 40/M-IND/PER/6/2016 yang digunakan untuk mengevaluasi lokasi kawasan industri yang ditunjuk di Sentolo $(70,2$ Ha). Uraian rinci disajikan pada tabel di bawah ini.

Tabel 6. Evaluasi Pemilihan Lokasi Kawasan Industri di Sentolo

\begin{tabular}{|c|c|c|c|}
\hline No & $\begin{array}{c}\text { Kriteria } \\
\text { Pemilihan } \\
\text { Lokasi }\end{array}$ & $\begin{array}{c}\text { Faktor } \\
\text { Pertimba- } \\
\text { ngan }\end{array}$ & Keterangan \\
\hline
\end{tabular}

\begin{tabular}{|c|c|c|c|}
\hline No & $\begin{array}{l}\text { Kriteria } \\
\text { Pemilihan } \\
\text { Lokasi }\end{array}$ & $\begin{array}{c}\text { Faktor } \\
\text { Pertimba- } \\
\text { ngan }\end{array}$ & Keterangan \\
\hline 1 & $\begin{array}{l}\text { Jarak ke } \\
\text { Pusat Kota }\end{array}$ & Min. $10 \mathrm{Km}$ & $\begin{array}{l}\text { - } \pm 15 \mathrm{~km} \text { ke Wates } \\
\text { (ibukota Kab } \\
\text { Kulon Progo) } \\
\text { - } \pm 20 \text { km ke } \\
\text { Yogyakarta } \\
\text { (ibukota DIY) }\end{array}$ \\
\hline 2 & $\begin{array}{l}\text { Jarak ke } \\
\text { Permukiman }\end{array}$ & Min. $2 \mathrm{~km}$ & $\begin{array}{l}\text { Tidak ada } \\
\text { permukiman di } \\
\text { daerah yang ditunjuk }\end{array}$ \\
\hline 3 & $\begin{array}{l}\text { Jaringan } \\
\text { transportasi } \\
\text { darat }\end{array}$ & $\begin{array}{l}\text { Jalan arteri } \\
\text { primer atau } \\
\text { jaringan } \\
\text { kereta api }\end{array}$ & $\begin{array}{l}\text { - Di sisi Utara, } \\
\text { dekat jalan arteri } \\
\text { yang } \\
\text { menghubungkan } \\
\text { Yogyakarta } \\
\text { - Di sisi Selatan, } \\
\text { dekat dengan } \\
\text { JJLS }\end{array}$ \\
\hline 4 & $\begin{array}{l}\text { Jaringan } \\
\text { Energi dan } \\
\text { Kelistrikan }\end{array}$ & Tersedia & $\begin{array}{l}\text { Sudah tersedia } \\
\text { sedikit jaringan } \\
\text { tenaga listrik di } \\
\text { daerah tersebut yang } \\
\text { rencananya akan } \\
\text { dikembangkan } \\
\text { dengan tenaga listrik } \\
\text { yang lebih besar }\end{array}$ \\
\hline 5 & $\begin{array}{l}\text { Jaringan } \\
\text { Telekomuni- } \\
\text { kasi }\end{array}$ & Tersedia & $\begin{array}{l}\text { Tersedia jaringan } \\
\text { kabel dan jaringan } \\
\text { telekomunikasi } \\
\text { nirkabel }\end{array}$ \\
\hline
\end{tabular}




\begin{tabular}{|c|c|c|c|}
\hline No & $\begin{array}{l}\text { Kriteria } \\
\text { Pemilihan } \\
\text { Lokasi } \\
\end{array}$ & \begin{tabular}{|c|} 
Faktor \\
Pertimba- \\
ngan
\end{tabular} & Keterangan \\
\hline 6 & $\begin{array}{l}\text { Prasarana } \\
\text { Angkutan }\end{array}$ & $\begin{array}{l}\text { Tersedia } \\
\text { pelabuhan } \\
\text { laut untuk } \\
\text { kelancaran } \\
\text { transporta- } \\
\text { si logistik } \\
\text { barang } \\
\text { maupun } \\
\text { outlet } \\
\text { ekspor/im- } \\
\text { por }\end{array}$ & $\begin{array}{l}\text { Belum ada } \\
\text { pelabuhan laut }\end{array}$ \\
\hline 7 & $\begin{array}{l}\text { Sumber air } \\
\text { baku }\end{array}$ & $\begin{array}{l}\text { Tersedia } \\
\text { sumber air } \\
\text { permukaan } \\
\text { (sungai, } \\
\text { danau, } \\
\text { waduk/em } \\
\text { bung, atau } \\
\text { laut) } \\
\text { dengan } \\
\text { debit yang } \\
\text { mencukupi }\end{array}$ & $\begin{array}{l}\text { Kurangnya } \\
\text { infrastruktur terkait } \\
\text { penyediaan air bersih } \\
\text { untuk aktivitas industri }\end{array}$ \\
\hline \multirow{5}{*}{8} & \multirow{5}{*}{ Kondisi Lahan } & $\begin{array}{l}\text { Topografi: } \\
\text { max. } 15 \%\end{array}$ & $\begin{array}{l}\text { Hampir seluruh area } \\
\text { terletak pada } \\
\text { kemiringan of } 5-8 \% \text {, } \\
\text { hanya sebagian kecil } \\
\text { terletak di }>15 \%\end{array}$ \\
\hline & & $\begin{array}{l}\text { Kesuburan } \\
\text { tanah } \\
\text { relatif tidak } \\
\text { subur (non- } \\
\text { irigasi } \\
\text { teknis) }\end{array}$ & $\begin{array}{l}\text { Kondisi tanah relatif } \\
\text { tidak subur }\end{array}$ \\
\hline & & $\begin{array}{l}\text { Pola tata } \\
\text { guna lahan: } \\
\text { nonpertani } \\
\text { an, non- } \\
\text { permukima } \\
\text { n, dan non- } \\
\text { konservasi }\end{array}$ & $\begin{array}{l}\text { Pola guna lahan saat } \\
\text { ini kebanyakan } \\
\text { digunakan untuk } \\
\text { kebun dan ladang }\end{array}$ \\
\hline & & $\begin{array}{l}\text { Ketersedia } \\
\text { an lahan } \\
\text { minimal } 50 \\
\text { ha }\end{array}$ & $\begin{array}{l}\text { Kawasan yang } \\
\text { ditunjuk seluas } 70,2 \\
\text { ha }\end{array}$ \\
\hline & & $\begin{array}{l}\text { Harga } \\
\text { lahan relatif } \\
\text { (bukan } \\
\text { merupakan } \\
\text { lahan } \\
\text { dengan } \\
\text { harga yang } \\
\text { tinggi di } \\
\text { daerah } \\
\text { tersebut) }\end{array}$ & $\begin{array}{l}\text { Data dari BPN } \\
\text { menyebutkan harga } \\
\text { tanah di bawah Rp } \\
500.000,00\end{array}$ \\
\hline
\end{tabular}

Sumber: Hasil analisa penulis

Pemilihan lokasi untuk kawasan industri harus mengacu pada perencanaan tata ruang
(RTRW) nasional dan daerah serta kesesuaian ruang. Kedua hal ini merupakan fondasi dasar bagi pengembangan kawasan industri yang menjamin kepastian implementasinya. Untuk keterangan lebih lanjut tentang lokasi kawasan industri potensial di Kabupaten Kulon Progo disajikan pada gambar di bawah ini.

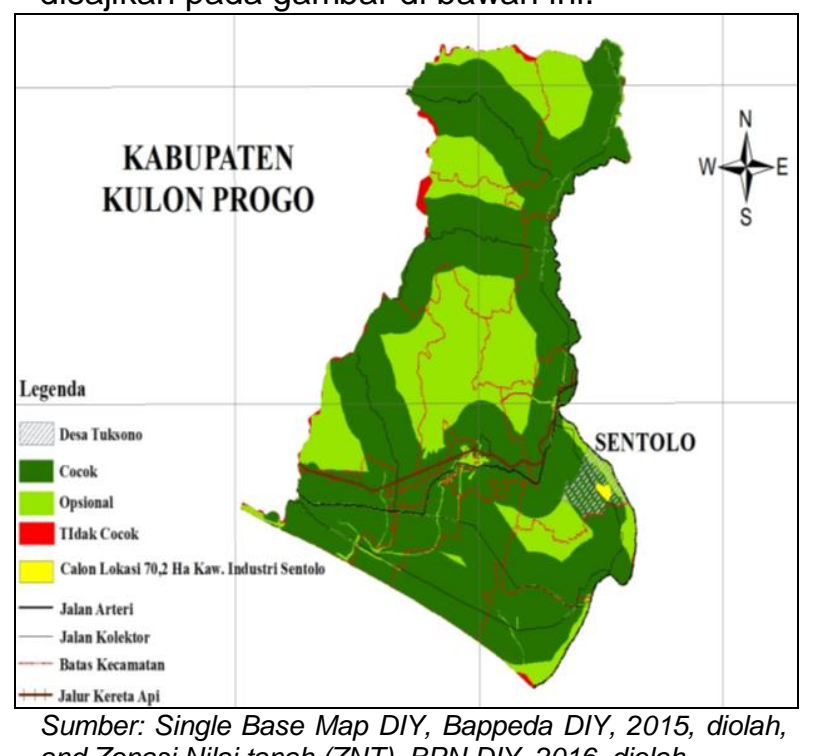
and Zonasi Nilai tanah (ZNT), BPN DIY, 2016, diolah

Gambar 2. Peta Analisa Kesesuaian Lokasi Kawasan Industri Berdasarkan Karakteristik Fisik dan Harga Lahan

Beberapa kriteria pemilihan lokasi industri digunakan dalam analisis peta di atas. Jarak ke permukiman, jarak ke pusat kota, jenis tanah (tidak produktif), kemiringan $(<15 \%)$, penggunaan lahan (non pertanian dan nonpermukiman) dan harga tanah dipilih sebagai variabel penting dalam analisis ini.

Dari hasil analisis peta, kawasan industri Sentolo seluas 70,2 Ha terletak di lokasi industri yang sesuai. Artinya, kawasan industri Sentolo memiliki karakteristik fisik yang sesuai sebagai syarat dasar pengembangan kawasan industri. Setelah melakukan analisa peta berdasarkan kriteria, hampir seluruh wilayah di Kabupaten Kulon Progo cocok untuk pengembangan kawasan industri. Selanjutnya, tahap persiapan dan pengembangan berikutnya tergantung pada upaya pemerintah mewujudkan kawasan industri ini. Kondisi lahan yang memadai harus diikuti dengan mendukung sarana dan prasarana dasar, sistem manajemen, komitmen dan upaya pemerintah untuk menyiapkan kawasan industri.

Selanjutnya, pengembangan kawasan industri di Sentolo akan dianalisa dan dievaluasi berdasarkan tahapan persyaratan yang ditentukan oleh Pemerintah Pusat maupun kasus di Jepang dan Korea. Untuk lebih lengkapnya, penjelasan dipaparkan pada tabel di bawah ini. 
Tabel 7. Hasil Evaluasi Persyaratan Kelayakan Kawasan Industri di Sentolo Berdasarkan Peraturan Pemerintah

\begin{tabular}{|c|c|c|c|c|c|}
\hline \multirow{2}{*}{ TAHAPAN } & \multirow{2}{*}{ RINCIAN } & \multirow{2}{*}{ KATA KUNCI } & \multicolumn{2}{|c|}{ KI Sentolo } & \multirow{2}{*}{ KETERANGAN } \\
\hline & & & Sesuai & Tidak & \\
\hline \multirow{3}{*}{$\begin{array}{l}\text { PERSIAP- } \\
\text { AN }\end{array}$} & Pemilihan Lokasi & $\begin{array}{l}\text { Identifikasi lahan yang sesuai } \\
\text { berdasarkan kriteria yang } \\
\text { ditentukan }\end{array}$ & $\checkmark$ & & $\begin{array}{l}\text { Sentolo memiliki kawasan } \\
\text { yang cocok untuk kawasan } \\
\text { industri }\end{array}$ \\
\hline & $\begin{array}{l}\text { Penyusunan } \\
\text { Dokumen }\end{array}$ & $\begin{array}{l}\text { Penyelesaian semua dokumen } \\
\text { yang dibutuhkan seperti master } \\
\text { plan, studi kelayakan }\end{array}$ & & $\checkmark$ & $\begin{array}{l}\text { Tidak ada rencana induk } \\
\text { yang pasti }\end{array}$ \\
\hline & $\begin{array}{l}\text { Pengurusan } \\
\text { Perijinan }\end{array}$ & $\begin{array}{l}\text { Pemenuhan semua izin yang } \\
\text { terkait dengan pengembangan } \\
\text { kawasan industri }\end{array}$ & & $\checkmark$ & Tidak semua izin terpenuhi \\
\hline \multirow[b]{2}{*}{$\begin{array}{l}\text { PENGEM- } \\
\text { BANGAN }\end{array}$} & Pembebasan Lahan & $\begin{array}{l}\text { Memetakan dan mengakuisisi } \\
\text { lahan yang sesuai }\end{array}$ & & $\checkmark$ & $\begin{array}{l}\text { Proses pembebasan lahan } \\
\text { belum selesai }\end{array}$ \\
\hline & $\begin{array}{l}\text { Penyusunan } \\
\text { Perencanaan Detail } \\
\text { Engineering Design } \\
\text { (DED) }\end{array}$ & $\begin{array}{l}\text { Pedoman pengembangan } \\
\text { kawasan industri }\end{array}$ & $\checkmark$ & & $\begin{array}{l}\text { Ada beberapa DED pada } \\
\text { beberapa rencana induk } \\
\text { sebelumnya }\end{array}$ \\
\hline \multirow{9}{*}{$\begin{array}{l}\text { PENGE- } \\
\text { LOLAAN }\end{array}$} & $\begin{array}{l}\text { Kelembagaan } \\
\text { Kawasan Industri }\end{array}$ & $\begin{array}{l}\text { Institusi yang mengelola dan } \\
\text { mengoperasikan kawasan } \\
\text { industri }\end{array}$ & & $\checkmark$ & Belum didirikan \\
\hline & Sistem Manajemen & $\begin{array}{l}\text { Berkaitan dengan kualitas, } \\
\text { keselamatan kerja, kesehatan, } \\
\text { dan manajemen energi }\end{array}$ & & $\checkmark$ & Belum didirikan \\
\hline & $\begin{array}{l}\text { Pelaksanaan Tata } \\
\text { Tertib Kawasan } \\
\text { Industri (Estate } \\
\text { Regulation) }\end{array}$ & $\begin{array}{l}\text { Mengendalikan hak dan } \\
\text { kewajiban penyewa }\end{array}$ & & $\checkmark$ & Belum didirikan \\
\hline & $\begin{array}{l}\text { Pelayanan kepada } \\
\text { Tenan }\end{array}$ & $\begin{array}{l}\text { Penyediaan utilitas pendukung } \\
\text { (gas, listrik, telekomunikasi, air, } \\
\text { dll) dan perawatan }\end{array}$ & & $\checkmark$ & Belum didirikan \\
\hline & Pemasaran & $\begin{array}{l}\text { Mempromosikan kawasan } \\
\text { industri dan tenan }\end{array}$ & & $\checkmark$ & Belum didirikan \\
\hline & $\begin{array}{l}\text { Pengembangan } \\
\text { Usaha }\end{array}$ & $\begin{array}{l}\text { Perencanaan pengembangan } \\
\text { usaha industri }\end{array}$ & & $\checkmark$ & Belum didirikan \\
\hline & $\begin{array}{l}\text { Pengelolaan } \\
\text { Lingkungan }\end{array}$ & Penggunaan utilitas yang efisien & & $\checkmark$ & Belum didirikan \\
\hline & $\begin{array}{l}\text { Kepedulian Sosial } \\
\text { dan Pemberdayaan } \\
\text { Masyarakat }\end{array}$ & $\begin{array}{l}\text { Memberikan dampak yang baik } \\
\text { pada masyarakat sekitar } \\
\text { kawasan industri }\end{array}$ & & $\checkmark$ & Belum didirikan \\
\hline & $\begin{array}{l}\text { Penyusunan dan } \\
\text { Pelaporan Data } \\
\text { Kawasan Industri }\end{array}$ & $\begin{array}{l}\text { Data kemajuan pengembangan } \\
\text { kawasan industri }\end{array}$ & & $\checkmark$ & Belum didirikan \\
\hline
\end{tabular}

Sumber: Hasil analisa penulis

Tabel 8. Hasil Evaluasi Persyaratan Kelayakan Kawasan Industri di Sentolo Berdasarkan Kasus di Jepang dan Korea Selatan

\begin{tabular}{|c|c|c|c|c|c|}
\hline \multirow{2}{*}{ TAHAPAN } & \multirow{2}{*}{ RINCIAN } & \multirow{2}{*}{ KATA KUNCI } & \multicolumn{2}{|c|}{ KI Sentolo } & \multirow{2}{*}{ KETERANGAN } \\
\hline & & & Sesuai & Tidak & \\
\hline \multirow{3}{*}{$\begin{array}{l}\text { PERSIAP- } \\
\text { AN }\end{array}$} & Pemilihan Lokasi & $\begin{array}{l}\text { Identifikasi lahan yang sesuai } \\
\text { berdasarkan kriteria yang } \\
\text { ditentukan }\end{array}$ & $\checkmark$ & & $\begin{array}{l}\text { Sentolo memiliki kawasan } \\
\text { yang cocok untuk kawasan } \\
\text { industri }\end{array}$ \\
\hline & $\begin{array}{l}\text { Penyusunan } \\
\text { Dokumen }\end{array}$ & $\begin{array}{l}\text { Penyelesaian semua dokumen } \\
\text { yang dibutuhkan seperti master } \\
\text { plan, studi kelayakan }\end{array}$ & & $\sqrt{ }$ & $\begin{array}{l}\text { Tidak ada rencana induk } \\
\text { yang pasti }\end{array}$ \\
\hline & $\begin{array}{l}\text { Pengurusan } \\
\text { Perijinan }\end{array}$ & $\begin{array}{l}\text { Pemenuhan semua izin yang } \\
\text { terkait dengan pengembangan } \\
\text { kawasan industri }\end{array}$ & & $\sqrt{ }$ & Tidak semua izin terpenuhi \\
\hline \multirow[b]{2}{*}{$\begin{array}{l}\text { PENGEM- } \\
\text { BANGAN }\end{array}$} & Pembebasan Lahan & $\begin{array}{l}\text { Memetakan dan mengakuisisi } \\
\text { lahan yang sesuai }\end{array}$ & & $\checkmark$ & $\begin{array}{l}\text { Proses pembebasan lahan } \\
\text { belum selesai }\end{array}$ \\
\hline & $\begin{array}{l}\text { Penyusunan } \\
\text { Perencanaan Detail } \\
\text { Engineering Design } \\
\text { (DED) }\end{array}$ & $\begin{array}{l}\text { Pedoman pengembangan } \\
\text { kawasan industri }\end{array}$ & $\sqrt{ }$ & & $\begin{array}{l}\text { Ada beberapa DED pada } \\
\text { beberapa rencana induk } \\
\text { sebelumnya }\end{array}$ \\
\hline
\end{tabular}




\begin{tabular}{|c|c|c|c|c|}
\hline TAHAPAN & RINCIAN & KATA KUNCI & KI Sentolo & KETERANGAN \\
\hline \multirow{9}{*}{$\begin{array}{l}\text { PENGELO- } \\
\text { LAAN }\end{array}$} & $\begin{array}{l}\text { Kelembagaan } \\
\text { Kawasan Industri }\end{array}$ & $\begin{array}{l}\text { Institusi yang mengelola dan } \\
\text { mengoperasikan kawasan } \\
\text { industri }\end{array}$ & $\checkmark$ & Belum didirikan \\
\hline & Sistem Manajemen & $\begin{array}{l}\text { Berkaitan dengan kualitas, } \\
\text { keselamatan kerja, kesehatan, } \\
\text { dan manajemen energi }\end{array}$ & $\checkmark$ & Belum didirikan \\
\hline & $\begin{array}{l}\text { Pelaksanaan Tata } \\
\text { Tertib Kawasan } \\
\text { Industri (Estate } \\
\text { Regulation) }\end{array}$ & $\begin{array}{l}\text { Mengendalikan hak dan } \\
\text { kewajiban penyewa }\end{array}$ & $\checkmark$ & Belum didirikan \\
\hline & $\begin{array}{l}\text { Pelayanan kepada } \\
\text { Tenan }\end{array}$ & $\begin{array}{l}\text { Penyediaan utilitas pendukung } \\
\text { (gas, listrik, telekomunikasi, air, } \\
\text { dil) dan perawatan }\end{array}$ & $\checkmark$ & Belum didirikan \\
\hline & Pemasaran & $\begin{array}{l}\text { Mempromosikan kawasan } \\
\text { industri dan tenan }\end{array}$ & $\checkmark$ & Belum didirikan \\
\hline & $\begin{array}{l}\text { Pengembangan } \\
\text { Usaha }\end{array}$ & $\begin{array}{l}\text { Perencanaan pengembangan } \\
\text { usaha industri }\end{array}$ & $\checkmark$ & Belum didirikan \\
\hline & $\begin{array}{l}\text { Pengelolaan } \\
\text { Lingkungan }\end{array}$ & Penggunaan utilitas yang efisien & $\checkmark$ & Belum didirikan \\
\hline & $\begin{array}{l}\text { Kepedulian Sosial } \\
\text { dan Pemberdayaan } \\
\text { Masyarakat }\end{array}$ & $\begin{array}{l}\text { Memberikan dampak yang baik } \\
\text { pada masyarakat sekitar } \\
\text { kawasan industri }\end{array}$ & $\checkmark$ & Belum didirikan \\
\hline & $\begin{array}{l}\text { Penyusunan dan } \\
\text { Pelaporan Data } \\
\text { Kawasan Industri }\end{array}$ & $\begin{array}{l}\text { Data kemajuan pengembangan } \\
\text { kawasan industri }\end{array}$ & $\checkmark$ & Belum didirikan \\
\hline
\end{tabular}

\section{Sumber: Hasil analisa penulis}

Pembangunan kawasan industri di Sentolo memiliki banyak ketidaksesuaian persyaratan seperti penjelasan di tabel 4.3 dan tabel 4.4. Dari persyaratan yang dinyatakan oleh pemerintah pusat atau kasus di Jepang dan Korea, hanya ada satu poin (kesesuaian lokasi) yang memenuhi persyaratan. Inilah sebabnya mengapa kemajuan pengembangan kawasan industri di Sentolo tidak berjalan dengan baik sampai sekarang.

Adanya beberapa rencana induk tanpa implementasi membuat arah pengembangan kawasan industri di Sentolo kurang terstruktur. Kemudian, adanya ketidakpastian kelembagaan atau institusi yang menangani proses pengembangan kawasan industri di Sentolo secara terus menerus. Oleh karena itu, harus ada divisi khusus yang mengelola dan memperhatikan keseluruhan perkembangan industri di Sentolo.

Prospek pengembangan Kawasan Industri Sentolo bergantung pada komitmen dan upaya pemerintah dalam proses implementasinya. Agar dapat mengembangkan kawasan industri di Sentolo, pemerintah daerah (Provinsi dan Kabupaten) harus secara serius mengenali dan memenuhi setiap persyaratan yang dianalisis dalam penelitian ini.

Mengingat hasil yang dianalisis dalam penelitian ini, sejumlah persyaratan harus dipenuhi untuk mendukung pengembangan kawasan industri yang ideal dari persiapan hingga tahap pengelolaan. Kondisi geografis di Sentolo sesuai untuk pengembangan kawasan industri menjadi syarat dasar atau tahap awal pengembangan kawasan industri. Hal ini haruslah segera ditopang dengan kelengkapan lainnya guna mempercepat implementasi kawasan industri ini.

\subsection{Kesimpulan}

Terdapat beberapa faktor yang mempengaruhi perkembangan kawasan industri di Sentolo. Berdasarkan pembahasan sebelumnya, yang paling terlihat adalah ketidakjelasan institusi yang secara spesifik menangani proses pengembangan kawasan industri di Sentolo. Selain itu, ada beberapa rencana induk yang tidak bisa dijadikan dasar atau pedoman pengembangan kawasan industri. Situasi ini menghambat pelaksanaan pembangunan kawasan industri di Sentolo.

Dalam pengembangan Kawasan Industri di Sentolo, kawasan ini hanya memiliki persyaratan dasar, yaitu kesesuaian lahan yang ada. Kemudian, lokasi yang sesuai ini memiliki prospek dan dapat menjadi tahap awal pengembangan kawasan industri di Sentolo. Selanjutnya, kondisi fisik yang memadai harus diikuti oleh persyaratan pendukung yang dijelaskan di bagian sebelumnya, dan juga disertai dengan komitmen dan insititusi khusus yang menangani pengembangan kawasan industri.

\subsection{Saran}

Untuk melaksanakan pengembangan kawasan industri ini di Sentolo, terdapat beberapa hal yang harus dilakukan, antara lain: 1. Menerapkan rencana induk tetap untuk 
Pengembangan Kawasan Industri Sentolo.

Sinkronisasi kebijakan pembangunan dari pemerintah pusat dan daerah merupakan keharusan untuk melaksanakan pengembangan kawasan industri ini dan untuk menjamin kepastian keberlanjutan pembangunan kawasan industri bagi investor/pengembang. Satu masterplan yang matang akan membantu mencegah kesalahpahaman bagi pihak pemerintah dan investor untuk mengimplementasikan kawasan industri. Selain itu, hal ini juga akan menjaga pengembangan kawasan industri sesuai rencana.

2. Membentuk divisi/ institusi khusus yang menangani pengembangan kawasan industri Mengikuti strategi pembangunan kawasan industri di Jepang dan Korea, pembentukan divisi khusus ini sangatlah penting. Divisi ini juga menerapkan strategi, taktik dan tindakan yang relevan terkait dengan pengembangan kawasan industri berdasarkan kebijakan dan peraturan yang berlaku, termasuk menarik investor, mengumpulkan informasi dan mengidentifikasi masalah. Selanjutnya, divisi ini akan menangani proses pengembangan kawasan industri dengan memantau dan mengevaluasi tahapan persiapan, pengembangan dan operasi.

3. Membentuk Tim Percepatan pengembangan kawasan industri

Berdasarkan Peraturan Pemerintah No. 24 tahun 2009, untuk mempercepat proses pengembangan kawasan industri, harus dibentuk tim untuk mengimplementasikan pembangunan kawasan industri. Tim ini terdiri dari beberapa institusi dari tingkat pemerintah pusat dan daerah yang mengurus proses pengembangan kawasan industri di wilayah tertentu. Karena Kabupaten Kulon Progo belum memiliki divisi khusus untuk pengembangan kawasan industri sampai sekarang, tim ini diharapkan dapat menangani pengembangan kawasan industri di Sentolo hingga tahap persiapan dan pengembangan.

\section{Daftar Pustaka}

[1] ASEAN-Japan Centre. List of Indonesian Industrial Estates ASEAN-Japan Centre http://www.asean.or.jp/ja/asean/know/countr $\mathrm{y} /$ indonesia/invest/industrialestate/index.ht $\mathrm{ml} /$ Diakses : 15 Juni 2017

[2] Badan Kerjasama dan Penanaman Modal DIY. (2013). Penyusunan Review Studi Kelayakan (FS) dan Masterplan Kawasan
Industri Sentolo Kabupaten Kulon Progo. Yogyakarta, Pemerintah Daerah DIY.

[3] Badan Pusat Statistik (BPS) Kulon Progo. (2016). Statistik Daerah Kecamatan Sentolo 2016. Wates, BPS Kulon Progo.

[4] Cho, H. (2012). Industrial Park Development Strategy and Management Practices: Ministry of Strategy and Finance, Republic of Korea.

[5] Fujimoto, K. (2013). Study on Approach of Local Government for Inviting Investment of Manufacturing Companies to Industrial Estate - Strategic Investment Invitation of Mie Prefecture. Mie University, Mie. (Japanese)「地方自治体における工業系企 業誘致の手法に関する研究 一三重県の戦略 的企業誘致」

[6] Gurusamy, S. (1994). An Analytical Study of The Problems of Small Scale Industrial Units in The Industrial Estates of Tamilnadu. (Ph.D.), Periyar University, Salem.

[7] Kementerian Perindustrian Republik Indonesia. (2012). Dokumen Masterplan Pengembangan Kawasan Industri Kulon Progo. Jakarta. Kementerian Perindustrian Republik Indonesia.

[8] Kementerian Perindustrian Republik Indonesia. (2013). Dokumen Perencanaan Pengembangan Kawasan Industri Di Provinsi DIY. Jakarta. Kementerian Perindustrian Republik Indonesia.

[9] Sugiyono. (2014). Metode Penelitian Manajemen Pendekatan Kuantitatif, Kualitatif, Kombinasi, Penelitian Tindakan, Penelitian Evaluasi. Alfabeta, Bandung.

[10]Wahidi D., Roestanto. (2014). Kawasan Industri Indonesia: Sebuah Konsep Perencanaan dan Aplikasinya. Biografika, Bogor.

Peraturan Pemerintah:

[1] Peraturan Pemerintah Republik Indonesia No. 24 Tahun 2009 tentang Kawasan Industri

[2] Peraturan Menteri Perindustrian no. 40/MIND/PER/6/2016 tentang Pedoman Teknis Kawasan Industri

[3] Peraturan Daerah Daerah Istimewa Yogyakarta Nomor 2 Tahun 2010 tentang Rencana Tata Ruang Wilayah/RTRW DIY Tahun 2009-2029

[4] Peraturan Daerah Kabupaten Kulon Progo Nomor 1 Tahun 2012 tentang Rencana Tata Ruang Tata Wilayah/RTRW Kabupaten Kulon Progo Tahun 2012 - 2032 